\title{
Identificação e diferenciação de herpesvírus bovino tipos 1 e 5 isolados de amostras clínicas no Centro-Sul do Brasil, Argentina e Uruguai (1987-2006) ${ }^{1}$
}

\author{
Mariana Sá e Silva², Mário Celso S. Brum², Rudi Weiblen ${ }^{3}$ e Eduardo F. Flores ${ }^{3 *}$ \\ ABSTRACT.- Silva M.S., Brum M.C.S., Weiblen R. \& Flores E.F. 2007. [Identification and \\ differentiation of herpesvirus types 1 and 5 isolated from clinical samples in central- \\ southern Brazil, Argentina and Uruguay (1987-2006).] Identificação e diferenciação de \\ herpesvírus bovino tipos 1 e 5 isolados de amostras clínicas no Centro-Sul do Brasil, Argentina \\ e Uruguai (1987-2006). Pesquisa Veterinária Brasileira 27(10):403-408. Departamento de Medicina \\ Veterinária Preventiva, Universidade Federal de Santa Maria, 97105-900 Santa Maria, RS, Brazil. \\ E-mail: flores@ccr.ufsm.br \\ Bovine herpesviruses types 1 and 5 (BoHV-1; BoHV-5) are genetically and antigenically closely \\ related such they can not be distinguished by routine diagnostic tests. As BoHV-1 has been \\ historically associated with respiratory and genital disease, herpesviruses isolated from these \\ clinical syndromes have been tentatively - and sometimes definitively - diagnosed as BoHV-1. \\ Likewise, cases of herpetic neurological infection in cattle have been generally attributed to \\ BoHV-5. This study reports the identification of 40 herpesvirus isolates from different clinical \\ specimens and syndromes in central-southern Brazil, Argentina and Uruguay (1987-2006) by \\ the use of a PCR able to differentiate between BoHV-1 and BoHV-5. BoHV-1 isolates $(n=16)$ \\ were identified in cases of respiratory disease $(n=3)$, vulvovaginitis and/or balanoposthitis \\ $(n=3)$, in semen of healthy bulls $(n=5)$ and in cases of neurological disease $(n=5)$. Viruses \\ identified as BoHV-5 $(n=24)$ were isolated predominantly from cases of neurological disease \\ $(n=21)$, but also from semen of healthy bulls $(n=2)$ and from a spleen of a calf with systemic \\ disease $(n=1)$. These results show that both BoHV-1 and BoHV-5 are not strictly associated \\ with their respective diseases; yet are frequently involved in clinical conditions otherwise \\ attributed to the other virus. These findings also reinforce the need of correctly identifying \\ the herpesvirus isolates as to better understand their pathogenesis and epidemiology.
}

INDEX TERMS: Bovine herpesvirus, BoHV-1, BoHV-5, differential diagnosis, epidemiology.

RESUMO.- Os herpesvírus bovino tipos 1 e 5 (BoHV-1; BoHV5) são genética e antigenicamente muito semelhantes e por isso são indistinguíveis pela maioria dos testes diagnósticos. Como o BoHV-1 tem sido classicamente associado com doença respiratória e genital, os herpesvírus isolados dessas enfermidades têm sido provisoriamente - e às vezes definitivamente - identificados como BoHV-1. Da mesma forma, os casos de infecção neurológica por herpesvírus em bovinos têm

\footnotetext{
${ }^{1}$ Recebido em 4 de abril de 2007.

Aceito para publicação em 25 de maio de 2007.

${ }^{2}$ Doutorando em Medicina Veterinária, Universidade Federal de Santa Maria (UFSM).

3 Departamento de Medicina Veterinária Preventiva, UFSM, Santa Maria, RS 97105-900, Brasil. *Autor para correspondência: flores@ccr.ufsm.br
}

sido atribuídos em sua totalidade ao BoHV-5. Este trabalho relata a identificação de 40 amostras de herpesvírus isoladas de diferentes casos clínicos na região Centro-Sul do Brasil, Argentina e Uruguai entre 1987 e 2006, pelo uso de um PCR capaz de diferenciar esses vírus. As amostras identificadas como BoHV-1 $(n=16)$ foram isoladas de doença respiratória $(n=3)$, balanopostite e/ou vulvovaginite $(n=3)$, do sêmen de touros saudáveis $(n=5)$ e de casos doença neurológica $(n=5)$. As amostras virais identificadas como BoHV-5 $(n=24)$ foram em sua maioria isoladas de doença neurológica $(n=21)$, mas também do sêmen de touros saudáveis $(n=2)$ e do baço de um bezerro com doença sistêmica $(n=1)$. Esses resultados demonstram que tanto o BoHV-1 como o BoHV-5 não estão estritamente associados às suas respectivas síndromes clínicas e que podem estar freqüentemente envolvidos em casos 
clínicos classicamente atribuídos ao outro vírus. Esses achados também reforçam a necessidade de se identificar corretamente os isolados de herpesvírus para um melhor conhecimento da sua patogenia e epidemiologia.

TERMOS DE INDEXAÇÃO: Herpesvírus bovino, BoHV-1, BoHV-5, diagnóstico diferencial, epidemiologia.

\section{INTRODUÇÃO}

Os herpesvírus bovino tipos 1 e 5 (BoHV-1; BoHV-5) pertencem à família Herpesviridae, subfamília Alphaherpesvirinae, gênero Varicellovirus e são geneticamente e antigenicamente muito semelhantes (Roizman et al. 1992). O BoHV-1 possui distribuição mundial, enquanto casos de meningoencefalite por BoHV-5 têm sido principalmente diagnosticados no Brasil (Weiblen et al. 1989, Salvador et al. 1998, Colodel et al. 2002, Rissi et al. 2006) e Argentina (Carrilo et al. 1983, Schudel et al. 1986). O BoHV-1 é considerado um dos agentes virais mais importantes de bovinos e tem sido associado historicamente com doença respiratória (rinotraqueíte infecciosa bovina, IBR), genital (vulvovaginite/balanopostite pustular infecciosa, IPV/IBP), reprodutiva e abortos (Kahrs 2001). O BoHV-5 foi reconhecido como uma espécie viral há poucos anos antes era considerado um subtipo do BoHV-1 - e tem sido associado com surtos de meningoencefalite em bovinos.

O BoHV-1 e o BoHV-5 compartilham diversas propriedades biológicas, antigênicas e moleculares e apresentam uma homologia de aproximadamente $85 \%$ no genoma (Delhon et al. 2003). Durante muitos anos, essas semelhanças representaram dificuldades para a classificação taxonômica, diagnóstico e epidemiologia desses agentes, pois impossibilitavam a distinção dos mesmos por testes virológicos e sorológicos de rotina (Bratanich et al. 1991, Roehe et al. 1997, Vogel et al. 2002, Kunrath et al. 2004). A diferença mais marcante entre esses vírus parece ser o potencial neuropatogênico distinto, uma característica fenotípica que reflete diferenças genéticas e moleculares ainda não esclarecidas (Chowdhury 1995, Delhon et al. 2003).

Apesar da grande similaridade, o BoHV-1 e o BoHV-5 podem ser diferenciados por análise de restrição enzimática do genoma, pelo perfil de polipeptídeos virais produzidos em células de cultivo, pela distinta reatividade com alguns anticorpos monoclonais (AcMs) e por testes de neutralização cruzada in vitro (Engels et al. 1986, Metzler et al. 1986, Bratanich et al. 1991, Roehe et al. 1997, D'Arce et al. 2002, Souza et al. 2002). Por meio dessas técnicas, isolados respiratórios de herpesvírus têm sido classificados como BoHV-1.1; os isolados de doença genital, como BoHV-1.2 (Metzler et al. 1986, D’arce et al. 2002); e os isolados de doença neurológica, pelas suas diferenças moleculares e antigênicas, como BoHV-5 (Roizman et al. 1992).

As amostras identificadas como BoHV-1 estão primariamente associadas com doença respiratória, genital e reprodutiva em bovinos de várias idades e doença sistêmica em bezerros recém-nascidos (Kahrs 2001). O BoHV-5 têm sido isolado principalmente de casos de doença neurológica fatal em bovinos, sobretudo em animais jovens (Salvador et al. 1998,
Colodel et al. 2002). No entanto, a associação desses vírus com as respectivas manifestações clínicas parece não ser exclusiva e mutuamente excludente. O BoHV-5 já foi detectado em casos de doença respiratória natural (Carrillo et al. 1983), no sêmen de touros saudáveis (Gomes et al. 2003), em tecidos de fetos abortados (Carrillo et al. 1983, Metzler et al. 1986) e em órgãos (baço e pulmão) em casos de infecções sistêmicas (Suarez et al. 1993). Além disso, a inoculação experimental do BoHV-5 em bezerros resulta em doença respiratória (Belknap et al. 1994, Vogel et al. 2004). O BoHV-1 também já foi detectado no encéfalo de bovinos, com ou sem doença neurológica sugerindo que o mesmo possa estar associado com doença neurológica (Furuoka et al. 1995; Ely et al. 1996, Roels et al. 2000, Penny et al. 2002).

A similaridade genotípica e fenotípica entre esses dois vírus pode acarretar em implicações epidemiológicas. Nesse sentido, a disponibilidade de técnicas para diferenciar os dois vírus, bem como uma delimitação mais precisa das manifestações clínicas associadas a cada um deles são importantes para o diagnóstico e controle dessas infecções.

O presente trabalho teve como objetivo identificar 40 amostras de herpesvírus obtidas de bovinos com diferentes afecções clínicas.

\section{MATERIAL E MÉTODOS}

Quarenta amostras de herpesvírus bovino oriundas de casos clínicos em quatro estados brasileiros (MS, RJ, RS e SP), Uruguai e Argentina entre 1987-2006 foram submetidas a um PCR desenvolvido para diferenciar BoHV-1 de BoHV-5 (Ashbaugh et al.1997). A utilização de dois primers específicos para a região codificante do gene da glicoproteína $\mathrm{C}(\mathrm{gC})$ resulta na amplificação de um produto de 653 pares de bases $(\mathrm{pb})$ para o BoHV-1 e de 589 pb para o BoHV-5 permitindo assim a diferenciação desses.

\section{Células e vírus}

As informações sobre a origem das amostras analisadas estão apresentadas no Quadro 1. Em 40 casos, os vírus foram identificados como herpesvírus pelo efeito citopático (ECP) típico produzido nos cultivos celulares, seguido de identificação com anticorpos policlonais (conjugados) ou monoclonais (AcMs) em técnicas de detecção de antígenos (imunofluorescência - IFA ou imunoperoxidase). A obtenção de DNA genômico viral para posterior amplificação e análise se deu a partir de isolados amplificados em células de linhagem de rim bovino (CRIB; Flores \& Donis 1995). Cepas de referência de BoHV-1 (Cooper) e BoHV-5 (SV-507/99) foram utilizadas como controle.

\section{Extração de DNA e protocolo do PCR}

Para a obtenção do DNA viral, células CRIB cultivadas em frascos de $25 \mathrm{~cm}^{2}$ foram inoculadas com 1 m.o.i. (multiplicidade de infecção) de cada vírus e coletadas por centrifugação quando o ECP atingia aproximadamente $80 \%$ do tapete. O DNA total foi extraído do sedimento celular utilizando-se o reagente DNAzol (Invitrogen) de acordo com as instruções do fabricante. Cada reação de PCR utilizou aproximadamente $1,5 \mu \mathrm{l}$ do DNA total extraído de células infectadas e $48,5 \mu \mathrm{l}$ de um mix contendo $15 \mathrm{pmol}$ dos primers, $10 \mathrm{mM}$ de dNTPs, $10 \%$ de DMSO, $5 \mu \mathrm{l}$ de tampão de reação $10 \mathrm{x}, 1 \mathrm{mM} \mathrm{de} \mathrm{MgCl}_{2}$ e $1 \mathrm{UI}$ da enzima Taq polimerase (Invitrogen). Os primers utilizados foram: forward 5'-GCGGGGGCTCGCCGAGGA-3' e reverse 5'-GGGAGCGCACGG TCAGGGGC-3'. Esse par de primers é complementar a seqüiências 
localizadas na região codificante do gene da glicoproteína $\mathrm{C}(\mathrm{gC})$. A sua utilização em PCR resulta na amplificação de um segmento de 653pb para o BoHV-1 e 589pb para o BoHV-5 (Ashbaugh et al. 1997). As condições utilizadas no PCR adaptadas das descritas por Ashbaugh et al. 1997 foram: $94^{\circ} \mathrm{C}$ por 5 min, seguido de 40 ciclos de denaturação $\left(94^{\circ} \mathrm{C}, 50 \mathrm{~s}\right)$, anelamento $\left(60^{\circ} \mathrm{C}, 55 \mathrm{~s}\right)$ e extensão $\left(72^{\circ} \mathrm{C}, 1 \mathrm{~min}\right)$. Os produtos da reação foram analisados sob luz ultravioleta após eletroforese em gel de agarose a $2 \%$ corado com brometo de etídio. O DNA total extraído de células infectadas com as cepas padrão Cooper e SV-507/99 foi utilizado como controle. O controle negativo se constituiu de DNA total extraído de células CRIB não infectadas. Os produtos de PCR dos isolados de BoHV-1 provenientes de doença neurológica, e do BoHV-5 isolado do baço e sêmen foram submetidos a sequienciamento. As sequiências obtidas foram comparadas, pelo Blast, com sequiências do BoHV-1 e BoHV-5 depositadas no GenBank (dados não apresentados).

\section{RESULTADOS}

A amplificação da região alvo do gene da gC a partir do DNA genômico de cada isolado resultou em amplicons de 653 ou $589 \mathrm{pb}$. O produto de $653 \mathrm{pb}$ corresponde ao segmento amplificado do genoma do BoHV-1 e apresentou o mesmo padrão de migração que o produto amplificado da cepa padrão Cooper (Fig.1). O produto obtido pela amplificação do segmento genômico dos isolados de BoHV-5 possuía 589pb e apresentou migração idêntica ao produto obtido da cepa padrão SV-507/ 99 (Fig. 1). Apenas uma banda (589 ou $653 \mathrm{pb}$ ) foi obtida pela amplificação do DNA de cada isolado, e as bandas de cada grupo de isolados não apresentaram variação de migração entre si (dados não apresentados). Esses resultados demonstram que o protocolo utilizado permite a amplificação específica de um fragmento de DNA do genoma cuja extensão varia entre o BoHV1 e BoHV-5, permitindo a distinção entre os dois vírus com base na extensão do produto obtido.

O Quadro 1 apresenta os resultados da identificação dos isolados com base no PCR diferencial e as informações referentes ao local de origem, material submetido para o diagnóstico e condição clínica associada com as respectivas amostras. Dentre as 40 amostras analisadas, 26 (65\%) foram isoladas ou detectadas no encéfalo de bovinos que apresentaram doença neurológica na forma de surtos ou de casos isolados. Dentre as 26 amostras isoladas de doença neurológica, 21

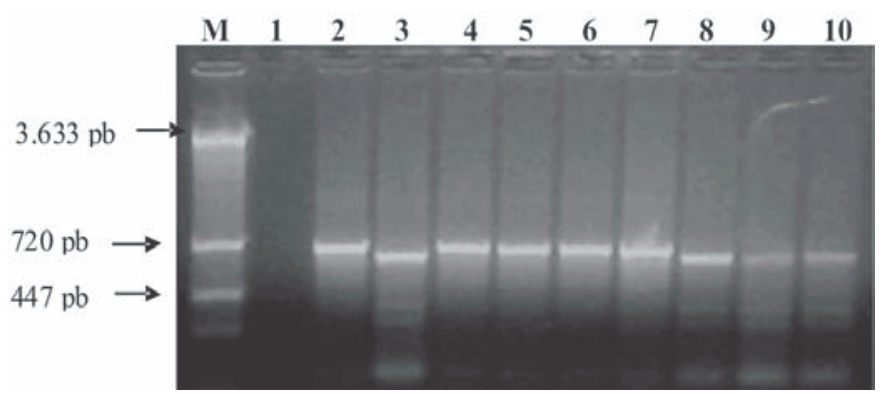

Fig.1. Amplificação parcial do gene $g C$ de BoHV. M: Marcador de massa molecular (p018 clivado com BamHI); Linha 1: controle negativo; Linha 2: Cooper; Linha 3: SV-507/99; Linha 4: SV-265/96; Linha 4: SV-56/90; Linha 5: SV-1613/93; Linha 6: CIAG04 1428; Linha 7: SV 371/05; Linha 8:SV-136/88; Linha 9: 002/00; Linha 10: CE05 18.
Quadro 1. Origem, histórico clínico e identificação molecular de amostras de herpesvírus bovino isoladas de espécimes clínicos na região Centro-Sul do Brasil, Argentina e Uruguai, 1987-2006

\begin{tabular}{|c|c|c|c|c|}
\hline Identificação & Origem & Histórico & Material & PCR gC \\
\hline \multicolumn{5}{|c|}{ Isolados de doença respiratória } \\
\hline EVI $123 / 98$ & MS $^{\mathrm{a}}$ & Doença respiratória & Suabe nasal & BoHV-1 \\
\hline SV-265/96 & $\mathrm{RS}^{\mathrm{b}}$ & Doença respiratória & Suabe nasal & BoHV-1 \\
\hline SV-371/05 & $\mathrm{RS}^{\mathrm{b}}$ & Doença respiratória & Suabe nasal & BoHV-1 \\
\hline \multicolumn{5}{|c|}{ Isolados de doença genital } \\
\hline SV-56/90 & $\mathrm{RS}^{\mathrm{b}}$ & Balanopostite & Lavado prepucial & BoHV-1 \\
\hline SV-453/93 & $\mathrm{RS}^{\mathrm{b}}$ & Vulvovaginite & Suabe vaginal & BoHV-1 \\
\hline SV-169/06 & $\mathrm{RS}^{\mathrm{d}}$ & Vulvovaginite & Suabe vaginal & BoHV-1 \\
\hline \multicolumn{5}{|c|}{ Isolados de sêmen e outros } \\
\hline $002 / 00$ & $\mathrm{RS}^{\mathrm{d}}$ & Doença sistêmica & Baço & BoHV-5 \\
\hline CE05 18 & $\mathrm{SP}^{\mathrm{C}}$ & Monitoramento de rotinz & Sêmen & BoHV-5 \\
\hline CIAG04 1428 & $\mathrm{SP}^{\mathrm{C}}$ & Monitoramento de rotinz & Sêmen & BoHV-1 \\
\hline CE05 63 & $\mathrm{SP}^{\mathrm{C}}$ & Monitoramento de rotinz & Sêmen & BoHV-5 \\
\hline ILAG 1354 & $\mathrm{SP}^{\mathrm{C}}$ & Monitoramento de rotin & Sêmen & BoHV-1 \\
\hline ILAG99 1359 & $\mathrm{SP}^{\mathrm{C}}$ & Monitoramento de rotin & Sêmen & BoHV-1 \\
\hline ILAG98 2542 & $\mathrm{SP}^{\mathrm{C}}$ & Monitoramento de rotin & Sêmen & BoHV-1 \\
\hline ILAG01 2420 & $\mathrm{SP}^{\mathrm{C}}$ & Monitoramento de rotin & Sêmen & BoHV-1 \\
\hline \multicolumn{5}{|c|}{ Isolados de doença neurológica } \\
\hline P160/87 & $\mathrm{RJ}^{\mathrm{a}}$ & Doença neurológica & Encéfalo & BoHV-5 \\
\hline EVI 88/95 & MS $^{\mathrm{a}}$ & Doença neurológica & Encéfalo & BoHV-5 \\
\hline EVI 340/96 & $\mathrm{MS}^{\mathrm{a}}$ & Doença neurológica & Encéfalo & BoHV-5 \\
\hline EVI 345/96 & $\mathrm{MS}^{\mathrm{a}}$ & Doença neurológica & Encéfalo & BoHV-5 \\
\hline P 96/160 & $\mathrm{RJ}^{\mathrm{a}}$ & Doença neurológica & Encéfalo & BoHV-5 \\
\hline Uruguai T2 & Uruguai $^{b}$ & Doença neurológica & Encéfalo & BoHV-5 \\
\hline Uruguai T3 & Uruguaib $^{b}$ & Doença neurológica & Encéfalo & BoHV-5 \\
\hline Uruguai T4 & Uruguai $^{\mathrm{b}}$ & Doença neurológica & Encéfalo & BoHV-5 \\
\hline $97 / 642$ & Argentina $^{b}$ & Doença neurológica & Encéfalo & BoHV-5 \\
\hline A 613 & Argentina $^{\mathrm{d}}$ & Doença neurológica & Encéfalo & BoHV-5 \\
\hline ISO $97 / 45$ & $\mathrm{MG}^{\mathrm{C}}$ & Doença neurológica & Encéfalo & BoHV-5 \\
\hline ISO $169 / 96$ & $\mathrm{SP}^{\mathrm{C}}$ & Doença neurológica & Encéfalo & BoHV-5 \\
\hline SV-136/88 & $\mathrm{RS}^{\mathrm{b}}$ & Doença neurológica & Encéfalo & BoHV-5 \\
\hline SV-1613/93 & $\mathrm{RS}^{\mathrm{b}}$ & Doença neurológica & Encéfalo & BoHV-1 \\
\hline SV-106/98 & $\mathrm{RS}^{\mathrm{b}}$ & Doença neurológica & Encéfalo & BoHV-5 \\
\hline SV-507/99 & $\mathrm{RS}^{\mathrm{b}}$ & Doença neurológica & Encéfalo & BoHV-5 \\
\hline SV-190/00 A & $\mathrm{MS}^{\mathrm{b}}$ & Doença neurológica & Encéfalo & BoHV-5 \\
\hline SV-55/02 & $\mathrm{RS}^{\mathrm{b}}$ & Doença neurológica & Encéfalo & BoHV-5 \\
\hline SV-299/03 & $\mathrm{RS}^{\mathrm{b}}$ & Doença neurológica & Encéfalo & BoHV-1 \\
\hline SV-609/03 & $\mathrm{RS}^{\mathrm{b}}$ & Doença neurológica & Encéfalo & BoHV-1 \\
\hline SV-437/04 & $\mathrm{RS}^{\mathrm{b}}$ & Doença neurológica & Encéfalo & BoHV-5 \\
\hline SV-47/05 & $\mathrm{RS}^{\mathrm{b}}$ & Doença neurológica & Encéfalo & BoHV-1 \\
\hline SV-198/05 & $\mathrm{RS}^{\mathrm{b}}$ & Doença neurológica & Encéfalo & BoHV-5 \\
\hline SV-41/06 & $\mathrm{MS}^{\mathrm{b}}$ & Doença neurológica & Encéfalo & BoHV-5 \\
\hline SV-63/06 & $\mathrm{RS}^{\mathrm{b}}$ & Doença neurológica & Encéfalo & BoHV-1 \\
\hline SV-344/06 & $\mathrm{MS}^{\mathrm{b}}$ & Doença neurológica & Encéfalo & BoHV-5 \\
\hline
\end{tabular}

As amostras foram isoladas ou cedidas por: ${ }^{a}$ Instituto de Pesquisas Veterinárias Desidério Finamor (IPVDF-Fepagro); b Setor de Virologia, UFSM; ' ${ }^{\circ}$ Instituto Biológico de São Paulo; ${ }^{\mathrm{d}}$ Universidade Federal de Pelotas (UFPel).

$(80,7 \%)$ foram identificadas como BoHV-5 e cinco $(19,3 \%)$ como BoHV-1. Duas amostras de BoHV-5 (CE 05-18 e CE 05-63) também foram identificadas entre os vírus isolados do sêmen de touros de centrais de inseminação artificial, procedimento de rotina para o monitoramento contínuo da qualidade e inocuidade do sêmen. Um herpesvírus isolado do baço de um bezerro com histórico de crescimento retardado e susceptibilidade a infeç̧ões também foi identificado como BoHV-5.

As três amostras isoladas de doença respiratória e os três isolados de doença genital foram identificadas como BoHV-1. 
A identidade dos cinco isolados de BoHV-1 associados com doença neurológica (SV-1613/93, SV-299/03, SV-609/03, SV-47/ 05 e SV-63/06), das amostras de BoHV-5 isoladas do sêmen (CE 05-18 e CE 05-63) e do baço (002/00) foi confirmada pelo seqüenciamento dos respectivos amplicons, seguido de alinhamento com as sequiências dos respectivos vírus depositadas no GenBank (dados não apresentados).

Os resultados obtidos demonstram que tanto o BoHV-1 como o BoHV-5 podem estar associados a quadros clínicos diferentes daqueles classicamente atribuídos a cada tipo viral, reforçando a necessidade de se proceder à correta identificação e diferenciação dos herpesvírus isolados de diferentes síndromes clínicas.

\section{DISCUSSÃO}

Este artigo relata a identificação e diferenciação mais abrangente de amostras de herpesvírus bovinos realizada no Brasil até o presente, envolvendo 35 isolados brasileiros, três uruguaios e dois argentinos. Os resultados deste estudo demonstram que o tanto o BoHV-1 como o BoHV-5 estão freqüientemente associados com manifestações clínicas que não aquelas classicamente atribuídas a cada uma destas espécies virais. Dentre os achados mais interessantes - e até certo ponto surpreendentes - está a associação do BoHV-1 com casos de doença neurológica (5 em 26 casos, 19,3\%), historicamente atribuídos ao BoHV-5. A presença freqüiente do BoHV-5 no sêmen de touros de centrais de inseminação artificial também merece destaque. Esses achados reforçam a necessidade de se identificar corretamente esses vírus após a sua deteç̧ão em amostras clínicas. A identificação e diferenciação destes vírus são de fundamental importância para o conhecimento de sua patogenia e epidemiologia.

Após aproximadamente duas décadas de confusão taxonômica e de nomenclatura, o BoHV-1 e o BoHV-5 foram classificados como duas espécies virais distintas (Roizman et al. 1992), devido a pequenas diferenças genéticas/moleculares e antigênicas (Engels et al. 1986, Metzler et al. 1986, Schudel et al. 1986). Além disso, pequenas diferenças detectadas entre amostras do BoHV-1 levaram a uma subdivisão: os isolados de doença respiratória foram classificados como BoHV-1.1 e aqueles envolvidos com doença genital foram denominados BoHV1.2 (Miller et al. 1991, Suarez et al. 1993). Posteriormente, outras subdivisões foram propostas (BoHV-1.2a e b) com bases em diferenças genômicas e antigênicas, porém ainda sem associação definitiva com parâmetros clínico-patológicos e/ ou epidemiológicos (Engels et al. 1986, Miller et al. 1991, D'Arce et al. 2002).

A estreita associação geralmente observada entre esses agentes e as respectivas síndromes clínicas, no entanto, pode ter ocasionalmente conduzido a conclusões diagnósticas equivocadas. Essa confusão deve-se à similaridade desses vírus em aspectos biológicos (como replicação em cultivo e ECP indistinguíveis) e antigênicos (reatividade sorológica cruzada por anticorpos policlonais e pela grande maioria dos AcMs), aliada com a dificuldade de se realizar a caracterização molecular a cada novo isolamento (Bratanich et al. 1991, Ashbaugh et al. 1997, Roehe et al. 1997, Oldoni et al. 2004,
Vogel et al. 2004). Assim, os herpesvírus isolados de doença respiratória e genital passaram a ser classificados provisoriamente - e às vezes definitivamente - como BoHV-1, mesmo sem confirmação molecular e/ou antigênica de sua identidade. $\mathrm{O}$ mesmo ocorreu com a etiologia das infecções neurológicas pelo herpesvírus bovino, que passaram a ser genericamente atribuídas ao BoHV-5. Diante dos resultados do presente trabalho, fica evidente que esses conceitos precisam ser revistos, pois tanto o BoHV-1 como o BoHV-5 estão associados com condições clínicas que não aquelas tradicionalmente a eles atribuídas.

O protocolo de PCR adaptado de Ashbaugh et al. (1997) permite a detecção e a concomitante identificação do agente, sendo por isso apropriado para o diagnóstico e diferenciação dessas infecções. Durante a padronização do teste, a especificidade da amplificação diferencial BoHV-1/BoHV-5 foi comprovada pela amplificação específica de 40 isolados de BoHV-1 e BoHV-5, previamente caracterizados por outras técnicas (Ashbaugh et al. 1997). Neste trabalho, os autores utilizaram um nested-PCR, com o objetivo de aumentar a sensibilidade para deteç̧ão de DNA viral diretamente em amostras clínicas, procedimento desnecessário quando o PCR é realizado a partir do DNA extraído de células inoculadas com o agente, como no caso do presente trabalho.

A região da $\mathrm{gC}$ utilizada para amplificação apresenta uma série de pequenas deleções que, no total, resultam em 64 nucleotídeos a mais na seqüiência de BoHV-1 em relação ao BoHV-5. Essa diferença permite uma diferenciação precisa entre os dois vírus pela diferença de tamanho dos amplicons, fato observado em todas as amostras por analisadas até o momento em nosso laboratório. A gC é uma das glicoproteínas com menor similaridade entre o BoHV-1 e BoHV-5, com apenas $75 \%$ de identidade, enquanto outras como a $\mathrm{gB}$ e a $\mathrm{gD}$ apresentam 93\% e 98\% de identidade, respectivamente (Delhon et al. 2003). Esta diferença torna a região um alvo adequado para diferenciação entre os isolados, seja por técnicas moleculares como PCR (Ashbaugh et al. 1997, Claus et al. 2005), ou pelo uso de AcMs específicos para esta glicoproteína (Chowdhury 1995, d'Offay et al. 1995, Oldoni et al. 2004). No presente trabalho, o seqüienciamento dos amplicons obtidos das sete amostras associadas com quadros atípicos também confirmou a especificidade da diferenciação. Da mesma forma, 15 entre as 40 amostras aqui analisadas já haviam sido caracterizadas por outros métodos, como análise de restrição e/ou reatividade com AcMs e apresentaram resultados equivalentes (Roehe et al. 1997, D'arce et al. 2002, Souza et al. 2002, Oldoni et al. 2004).

Apenas um isolado (SV-1613/93) dos 15 já anteriormente caracterizados apresentou discordância com o presente estudo. Esse isolado havia sido reconhecido por um AcM que, a princípio, reagia somente com isolados de BoHV-5 e fracamente com uma cepa de referência do BoHV-1 (Oldoni et al. 2004). Entretanto, as técnicas utilizadas no presente estudo PCR e seqüenciamento do amplicon - identificaram esse isolado inequivocamente como BoHV-1. O AcM utilizado por Oldoni et al. (2004) possivelmente é direcionado para um epitopo da gC que é conservado entre isolados de BoHV-5 e 
que apresenta alguma similaridade em determinadas amostras de BoHV-1, podendo assim apresentar reatividade com esses vírus.

Além do protocolo utilizado neste trabalho, outras descrições de diferenciação de BoHV-1 e BoHV-5 por PCR baseadas em regiões com baixa similaridade entre esses vírus foram relatadas. Outra região da $\mathrm{gC}$, que também apresenta deleções que permitem a diferenciação pela variação de tamanho dos amplicons, foi descrita e apresenta uma confiabilidade elevada (Claus et al. 2005). Outros trabalhos descrevem a utilização do gene da timidina kinase (TK) isoladamente (Moore et al. 2000), amplificação de uma região da TK associada com restrição enzimática do amplicon (d'Offay et al. 1995), ou ainda amplificação de região da TK associada com uma seqüência do gene da gD (Alegre et al. 2001). De qualquer forma, a diferenciação de BoHV-1 e BoHV-5 pelo uso de PCR - em protocolos padronizados para uso direto em amostras clínicas ou após o isolamento do vírus em cultivo - apresenta vantagens em relação aos métodos anteriores (análise de restrição enzimática, perfil de polipeptídeos virais). A identificação por AcMs também pode ser adequada para esse propósito desde que se disponha de anticorpos estritamente específicos para cada um destes agentes (Suarez et al. 1993, D'Arce et al. 2002, Souza et al. 2002, Oldoni et al. 2004).

Dentre as 26 amostras oriundas de doença neurológica analisadas, 21 foram identificados como BoHV-5, confirmando a estreita associação desse vírus com meningoencefalite em bovinos. No entanto, cinco isolados de doença neurológica foram identificados como BoHV-1, um achado pouco freqüiente até o presente. A identidade desses vírus foi confirmada pelo seqüenciamento e restrição enzimática dos amplicons, por testes de neutralização cruzada e por análise de reatividade com AcMs (Silva et al. 2007). Ou seja, as amostras de herpesvírus isoladas de doença neurológica identificadas pelo PCR no presente estudo são inequivocamente BoHV-1. Embora o BoHV-1 já tenha sido ocasionalmente isolado do encéfalo de bovinos, associado ou não com doença neurológica (d'Offay et al. 1995, Ely et al. 1996, Roels et al. 2000, Penny et al. 2002), o presente estudo demonstra que a freqüência de envolvimento do BoHV-1 com doença neurológica é maior do que anteriormente relatado. Esses achados indicam a necessidade de se considerar sempre o BoHV-1 como suspeito em casos de doença neurológica, embora o BoHV-5 seja o mais freqüentemente envolvido.

Outros achados atípicos do presente estudo foram as amostras de BoHV-5 isoladas do sêmen de touros sadios, embora estudos anteriores já tenham relatado o isolamento do BoHV-5 do sêmen (Gomes et al. 2003). Além da presença do BoHV-5 no sêmen, a deteç̧ão desse vírus no baço de um bovino com doença sistêmica provavelmente reflete a capacidade do vírus produzir viremia, mesmo transitória e em baixos níveis. Alguns trabalhos também relataram a detecção do BoHV-5 em outros tecidos, como pulmão, baço e tecidos de fetos abortados (d'Offay et al. 1993, Suarez et al. 1993).

Em resumo, os resultados obtidos neste trabalho demonstram que tanto o BoHV-1 como o BoHV-5 estão envolvidos com frequiência com condições clínico-patológicas classica- mente atribuídas a outra espécie de BoHV. Isso reforça a necessidade de se identificar e distinguir corretamente estes vírus após a sua deteç̧ão em amostras clínicas. Nesse sentido, o PCR utilizado no presente estudo demonstrou ser adequado para a identificação e diferenciação entre o BoHV-1 e BoHV-5 e assim pode ser utilizado na rotina de diagnóstico dessas infecções.

Agradecimentos.- Aos Drs Paulo M. Roehe, Edwiges Maristela Pituco, Silvia de Oliveira Hübner e Anselmo Odeon pelas amostras virais caracterizadas. E.F.F. e R.W. são bolsistas de produtividade em pesquisa do CNPq (101666/ 2004-0, 301339/2004-0); M.S.S. possui bolsa de doutorado da CAPES e M.C.S.B. possui bolsa de doutorado do CNPq.

\section{REFERÊNCIAS}

Alegre M., Nanni M. \& Fondevila N. 2001. Development of a multiplex polymerase chain reaction for the differentiation of bovine herpesvirus-1 and 5. J. Vet. Med. 48:613-621.

Ashbaugh S.E., Thompson K.E., Belknap E.B., Schultheiss P.C., Chowdhury S. \& Collins J.K. 1997. Specific detection of shedding and latency of bovine herpesvirus 1 and 5 using a nested polymerase chain reaction. J. Vet. Diagn. Invest. 9:387-394.

Belknap E.B., Collins J.K., Ayers V.K. \& Schultheiss P.C. 1994. Experimental infection of neonatal calves with neurovirulent bovine herpesvirus type 1.3. Vet. Path. 31:358-365.

Bratanich A.C., Sardi S.I., Smitsaart E.N. \& Schudel A.A. 1991. Comparative studies of BHV-1 variants by in vivo-in vitro tests. J. Vet. Med. B 38:41-48.

Carrillo B.J., Ambrogí A., Schudel A.A. Vazquez M., Dahme E. \& Pospischil A. 1983. Meningoencephalitis caused by IBR virus in calves in Argentina. Zbl. Vet. Med. B 30:327-332.

Chowdhury S. 1995. Molecular basis of antigenic variation between the glycoproteins $\mathrm{C}$ of respiratory bovine herpesvirus 1 (BHV-1) and neurovirulent BHV-5. Virology 213:558-568.

Claus M.P., Alfieri A.F., Folgueras-Flatschart A.V., Wosiacki S.R., Medici K.C. \& Alfieri A.A. 2005. Rapid detection and differentiation of bovine herpesvirus 1 and 5 glycoprotein $\mathrm{C}$ gene in clinical specimens by multiplex-PCR. J. Virol. Methods 128:183-188.

Colodel E.M., Nakazato L., Weiblen R., Mello R.M., Silva R.R.P., Souza M.A., Filho J.A.O. \& Caron L. 2002. Meningoencefalite necrosante em bovinos causada por herpesvírus bovino no estado de Mato Grosso do Sul, Brasil. Ciência Rural, Santa Maria, 32:293-298.

D’Arce R.C.F., Almeida R.S., Silva T.C., Franco A.C., Spilki F., Roehe P.M. \& Arns C.W. 2002. Restriction endonuclease and monoclonal antibodies analysis of Brazilian isolates of bovine herpesvirus types 1 and 5. Vet. Microbiol. 88-315-324.

d'Offay J.M., Mock R.E. \& Fulton R.W. 1993. Isolation and characterization of encephalitic bovine herpesvirus type 1 isolates from cattle in North America. Am. J. Vet. Res. 54:534-539.

d'Offay J.M., Ely R.W., Baldwin C.A., Whitenack D.L., Stair E.L. \& Collins J.K. 1995. Diagnosis of encephalitic bovine herpesvirus type 5 (BHV-5) infection in cattle: virus isolation and immunohistochemical detection of antigen in formalin-fixed bovine brain tissues. J. Vet. Diagn. Invest. 7:247-251.

Delhon G., Moraes M.P., Lu Z., Afonso C.L., Flores E.F., Weiblen R., Kutish G.F. \& Rock D.L. 2003. Genome of bovine herpesvirus 5. J. Virol. 77:1033910347.

Engels M., Giuliani C., Wild P., Beck T.M., Loepfe E. \& Wyler R. 1986. The genome of bovine herpesvirus 1 (BHV-1) strains exhibiting a neuropathogenic potential compared to known BHV-1 strains by restriction site mapping and cross-hybridization. Virus Res. 6:57-73.

Ely R.W., d’Offay J.M., Ruefer A.H. \& Cash C.Y. 1996. Bovine herpesviral encephalitis: a retrospective study on archived formalin-fixed, paraffinembedded brain tissue. J. Vet. Diagn. Invest. 8:487-492. 
Flores E.F. \& Donis R. 1995. Isolation of a mutant MDBK cell line resistant to bovine virus diarrhea virus (BVDV) due to a block in viral entry. Virology 208:565-575.

Furuoka H., Izumida N., Horiuchi M., Osame S., \& Matsui T. 1995. Bovine herpesvirus meningoencephalitis association with infectious bovine rhinotracheitis (IBR) vaccine. Acta Neuropathol. 90:565-571.

Gomes L.I., Rocha M.A., Souza J.G., Costa E.A. \& Barbosa-Stancioli E.F. 2003. Bovine herpesvirus 5 (BoHV-5) in bull semen: amplification and sequence analysis of the US4 gene. Vet. Res. Commun. 27:495-504.

Kahrs R.F. 2001. Infectious bovine rhinotracheitis pustular vulvovaginitis, p.159-170. In: Idem (ed.), Viral Disease of Cattle. 2th ed. Iowa State University Press, Ames.

Kunrath C.F., Vogel F.S.F., Oldoni I., Flores E.F., Weiblen R., Dezengrini R., Torres F.D. \& Pan K.A. 2004. Soroneutralização e imunofluorescência utilizando anticorpos monoclonais no diagnóstico rápido de infecções pelo herpesvírus bovino tipos 1 e 5 (BoHV-1 e BoHV-5). Ciência Rural, Santa Maria, 34:1877-1883.

Metzler A.E., Schudel A.A. \& Engels M. 1986. Bovine herpesvirus 1: molecular and antigenic characteristics of variant viruses isolated from calves with neurological disease. Arch. Virol. 87:205-217.

Miller J.M., Whetstone C.A. \& Van der Maaten M.M. 1991. Abortifacient property of bovine herpesvirus type 1 isolates that represent three subtypes determined by restriction endonuclease analysis of viral DNA. Am. J. Vet. Res.52:458-461.

Moore S., Gunn M. \& Walls D. 2000. A rapid and sensitive PCR-based diagnostic assay to detect bovine herpesvirus 1 in routine diagnostic submissions. Vet. Microbiol. 75:145-153.

Oldoni I., Weiblen R., Inkelmann M.A. \& Flores E.F. 2004. Production and characterization of monoclonal antibodies to a Brazilian bovine herpesvirus type 5. Braz. J. Med. Biol. Res. 37:213-221.

Penny C.D., Howie F., Nettleton P.F. \& Schock A. 2002. Upper respiratory disease and encephalitis in neonatal beef calves caused by bovine herpesvirus type 1 . Vet. Rec. 151:89-91

Rissi D.R., Oliveira F.N., Rech R.R., Pierezan F., Lemos R.A.A. \& Barros C.S.L. 2006. Epidemiologia, sinais clínicos e distribuição das lesões encefálicas em bovinos afetados por meningoencefalite por herpesvírus bovino-5. Pesq. Vet. Bras. 26:123-132.
Roehe P.M., Silva T.C., Nardi N.B., Oliveira L.G. \& Rosa J.C.A. 1997. Diferenciação entre o vírus da rinotraqueíte infecciosa bovina (BHV-1) e o herpesvírus da encefalite bovina (BHV-5) com anticorpos monoclonais. Pesq. Vet. Bras. 17:41-44.

Roels S., Charlier G., Letellier C., Meyer G., Schynts F., Kerkhofs P., Thiry E. \& Vanopdenbosch E. 2000. Natural case of bovine herpesvirus 1 meningoencephalitis in an adult cow. Vet. Rec. 146:586-588.

Roizman B., Desrosiers R.C., Fleckenstein B., Lopez C., Minson A.C. \& Studdert M.J. 1992. The family Herpesviridae: an update. Arch. Virol. 123:425-449.

Salvador S.W.C., Lemos R.A.A., Riet-Correa F., Roehe P.M. \& Osorio A.L.A.R. 1998. Meningoencefalite em bovinos causada por herpesvírus bovino-5 no Mato Grosso do Sul e São Paulo. Pesq. Vet. Bras. 18:76-83.

Schudel A.A., Carrillo B.J., Wyler R. \& Metzler A.E. 1986. Infections of calves with antigenic variants of bovine herpesvirus 1 (BHV-1) and neurological disease. J. Vet. Med. B. 33:303-310.

Silva M.S., Brum M.C.S., Weiblen R. \& Flores E.F. 2007 Biological, antigenic and molecular characterization of bovine herpesvirus type 1 (BoHV-1) isolates associated with neurological disease in cattle. Virus Research (In press)

Souza V.F., Melo S.V., Esteves P.A., Schmidt C.S., Gonçalves D.A., Schaefer R., Silva T.C., Almeida R.S., Vicentini F., Franco A.C., Oliveira E.A., Spilki F.R., Weiblen R., Flores E.F., Lemos R.A., Alfieri A.A., Pituco E.M. \& Roehe P.M. 2002. Caracterização de herpesvírus bovinos tipos 1 (BHV-1) e 5 (BHV-5) com anticorpos monoclonais. Pesq. Vet. Bras. 22:13-18.

Suarez A.H., Metzler A.E., Weiblen R., Berrios P. \& Schudel A.A. 1993. Molecular characterization of south american bovine herpesvirus-1 isolates with monoclonal antibodies and SDS-PAGE. J. Vet. Med. B. 40:125-130.

Vogel F.S.F., Flores E.F., Weiblen R. \& Kunrath C.F. 2002. Atividade neutralizante anti-herpesvírus bovino tipos 1 (BHV-1) e 5 (BHV-5) no soro de bovinos imunizados com vacinas contra o BHV-1. Ciência Rural 32:881-883.

Vogel F.S.F., Lima M., Flores E.F., Weiblen R., Winkelmann E.R., Mayer S.V., Mazzutti K.C. \& Arenhart S. 2004. Replicação e excreção viral durante a infecção aguda e após a reativação da latência induzida por dexametasona em bezerros inoculados com os herpesvírus bovinos tipo 1 (BHV-1) e 5 (BHV-5). Ciência Rural, Santa Maria, 34:1619-1621.

Weiblen R., de Barros C.S., Canabarro T.F. \& Flores E.F. 1989. Bovine meningoencephalitis from IBR virus. Vet. Rec. 124:666-667. 